\title{
PENGARUH EKSTRAK DAUN BINTARO (Cerbera odollam) TERHADAP WAKTU BERHENTI MAKAN DAN MORTALITAS LARVA ULAT GRAYAK (Spodoptera litura)
}

\author{
Turhadi $^{1 \bullet}$, Bedjo $^{2}$, Suharjono $^{3}$ \\ ${ }^{1}$ Pusat Penelitian Bioteknologi dan Bioindustri Indonesia (PPBBI), Bogor Indonesia; ${ }^{2}$ Balai Penelitian Tanaman Aneka \\ Kacang dan Umbi (BALITKABI), Malang, Indonesia; ${ }^{3}$ Jurusan Biologi Fakultas Matematika dan Ilmu Pengetahuan Alam \\ Universitas Brawijaya, Malang, Indonesia \\ `Email korespondensi: turhadibiologi@gmail.com
}

\begin{abstract}
The negative effects caused by chemical pesticides to ecosystem and environment encourage efforts to suppress its use, one of which is through plant biopesticides. As one of the important pest of crops, the population of armyworm (Spodoptera litura) needs to be suppressed to minimize crop loss. One of plant that can be used as plant biopesticides to control armyworm population is bintaro (Cerbera odollam).This study aimed to determine the potential of bintaro leaf as plant biopesticides on stop feeding and mortality of armyworm larvae.This study was designed using a complete randomized design and consisting of six levels of treatment (0 (control), 10, 15, 20,25 , and $30 \mathrm{~g} / \mathrm{L}$ ) and each treatment was repeated in triplicates. The extract was applied to the armyworm larvae using leaf dipping method. The effectiveness of bintaro leaf extract on armyworm was done by observing time of stop feeding and larval mortality. The results showed that bintaro leaf extract has potential to be used as a plant biopesticide toS. litura larvae population controlling. The mortality of S. litura larvae increased with the increasing time of extract application.In addition, the highest mortality of armyworm larvae occurred in the treatment of 20, 25, and $30 \mathrm{~g} / \mathrm{L}$ that was equal to $40 \%$ at 168 hours after application.
\end{abstract}

Keywords: biopesticide, C. odollam, S. litura

\begin{abstract}
Abstrak. Efek negatif yang ditimbulkan oleh pestisida kimia terhadap ekosistem dan lingkungan mendorong usaha untuk menekan penggunaannya, salah satunya melalui penggunaan biopestisida nabati. Sebagai salah satu hama penting tanaman pertanian, ulat grayak (Spodoptera litura) perlu untuk ditekan populasinya untuk meminimalisir kehilangan hasil panen. Salah satu tanaman yang dapat dimanfaatkan sebagai biopestisida nabati untuk mengendalikan hama ulat grayak yaitu Cerbera odollam. Penelitian ini bertujuan untuk mengetahui potensi biopestisida nabati daun bintaro terhadap waktu berhenti makan (stop feeding) dan mortalitas larva ulat grayak. Penelitian ini didesain menggunakan rancangan acak lengkap yang terdiri dari enam taraf perlakuan ( 0 (kontrol), 10, 15, 20, 25, dan $30 \mathrm{~g} / \mathrm{L}$ ) dan masing-masing perlakuan diulang tiga kali. Ekstrak diaplikasikan ke larva ulat grayak dengan menggunakan metode leaf dipping methods. Efektivitas pengaruh ekstrak daun bintaro terhadap ulat grayak dilakukan dengan mengamati waktu berhenti makan (time of stop feeding) dan mortalitas (tingkat kematian larva). Hasil penelitian menunjukkan bahwa ekstrak daun bintaro berpotensi digunakan sebagai biopestisida nabati untuk larva S. litura. Mortalitas larva S. litura semakin meningkat sejalan dengan semakin lamanya waktu aplikasi ekstrak. Selain itu, mortalitas larva ulat grayak tertinggi terjadi pada perlakuan 20, 25, dan $30 \mathrm{~g} / \mathrm{L}$ yaitu sebesar $40 \%$ pada 168 jam setelah aplikasi.
\end{abstract}

Kata kunci: biopestisida, C. odollam, S. litura

\section{PENDAHULUAN}

Dampak negatif akibat penggunaan pestisida kimia perlu ditekan, salah satunya melalui pemanfaatan pestisida yang dinilai aman bagi ekosistem dan lingkungan. Pemanfaatan agen pengendalian hayati berupa biopestisida dalam upaya mendukung pengelolaan hama dan penyakit secara terpadu dapat memberikan hasil yang optimal dan relatif aman bagi sekitar (Asmaliyah et al., 2010). Biopestisida merupakan pestisida yang bersumber dari bahan-bahan alami seperti tumbuhan, hewan, dan mikroba yang umumnya bersifat mudah terurai sehingga lebih aman dan tidak mencemari lingkungan (Marrone, 2019; Mboussi, Ambang, Kakam, \& Beilhe, 2018).

Telah diketahui bahwa berbagai tanaman mempunyai potensi sebagai biopestisida, misalnya Tephrosia vogelii, Annona squamosa, Cinnamomum multiforum (Abizar \& Prijono, 2010; Sifa, Prijono, \& Rauf, 2013), Piper cubeba (Abizar \& Prijono, 2010), Tagetes erecta (Salinas-Sánchez et al., 2012), Acorus calamus, Alpinia galanga, Curcuma longa, Piper nigrum, Piper retrofractum, dan Sphagneticola trilobata (Yooboon, Pengsook, Ratwatthananon, Pluempanupat, \& Bullangpoti, 2019), dan lain sebagainya. 
Salah satu flora yang banyak tumbuh di wilayah Indonesia serta mempunyai potensi sebagai biopestisida nabati adalah tanaman bintaro (Cerbera odollam). Tanaman bintaro berpotensi sebagai antioksidan, sitotoksik, antifungal, antimikroba, dan insektisida (Chu, Singh, Ahmad, \& Mamat, 2015; Rahman, Faisal, Hasan, Ahsan, \& Masud, 2017; Rizal, Dewi, \& Utomo, 2015; Susilo, Haryanta, \& Sa'adah, 2019). Tanaman bintaro juga telah dilaporkan sebelumnya berpotensi sebagai biopestisida terhadap Pteroma plagiophleps (Utami, 2010), Spodoptera litura F (Sa'diyah, Purwani, \& Wijayawati, 2013; Somsroi \& Chaiyong, 2016; Utami, 2010), dan Riptortus linearis (Susilo et al., 2019). Daun tanaman bintaro memiliki senyawa metabolit sekunder seperti saponin, polifenol, alkaloid, steroid, terpenoid, flavonoid, dan tanin(Chu et al., 2015; Sholahuddin, Subchan, \& Prihatin, 2018; Utami, 2010). Dibandingkan organ akar dan buah, daun mempunyai biomassa yang lebih melimpah. Berdasarkan hal tersebut maka daun dipilih sebagai sumber biopestisida nabati pada penelitian ini. Tujuan penelitian ini yaitu untuk mengetahui potensi biopestisida nabati daun bintaro terhadap waktu berhenti makan (stop feeding) dan mortalitas larva ulat grayak. Hasil penelitian ini diharapkan dapat dijadikan alternatif dalam pengendalian hama sehingga penggunaan insektisida sintetik atau kimia dapat dikurangi.

\section{METODE}

\section{Perbanyakan dan Pemeliharaan Larva Ulat Grayak (Spodoptera litura)}

Telur ulat grayak (Gambar 1.) yang dikoleksi dari Kebun Percobaan Kendalpayak, Balai Penelitian Tanaman Aneka Kacang dan Umbi (BALITKABI), Malang ditempatkan dalam toples sampai menunjukkan perkembangan menjadi larva instar tiga. Larva instar ketiga tersebut digunakan untuk pengujian. Selama pemeliharaan larva diberi pakan berupa daun kedelai yang setiap hari diganti dengan pakan yang baru.



Gambar 1. Daun kedelai yang terserang larva (ditunjukkan dengan lingkaran warna merah) (a) dan telur Spodoptera litura yang diperoleh dari lapang (ditunjukkan dengan tanda panah warna hitam). Bar menunjukkan $1 \mathrm{~cm}$.

\section{Pembuatan Ekstrak Daun Bintaro (Cerbera odollam)}

Daun bintaro yang digunakan untuk pembuatan ekstrak diperoleh dari area sekitar wilayah Universitas Brawijaya, Malang. Daun yang telah diambil kemudian dicuci dengan air dan dikering anginkan selama satu minggu. Setelah kering, daun tersebut dipotong-potong kecil dan dihaluskan dengan menggunakan blender hingga menjadi serbuk halus.

Serbuk halus yang diperoleh selanjutnya direndam dengan menggunakan akuades selama 72 jam. Setelah 72 jam maka rendaman ekstrak disaring dengan menggunakan corong Buchner yang dialasi kertassaring dan filtrat hasil saringan ditampung dalam labu erlenmeyer (Hasnah, Husni, \& Fardhisa, 2012).

\section{Rancangan Percobaan}

Rancangan percobaan yang digunakan adalah Rancangan Acak Lengkap yang terdiri 
dari enam taraf perlakuan ekstrak yaitu 0 (kontrol), 10, 15, 20, 25, dan 30 g/L. Tiap perlakuan dilakukan sebanyak tiga ulangan.

\section{Metode Pengujian}

Pengujian dilakukan dengan metode pencelupan daun (leaf dipping method) (Erdogan, Yildirim, \& Sever, 2012). Daun kedelai selanjutnya direndam pada masingmasing konsentrasi larutan ekstrak selama 1 jam, setelah itu dikering-anginkan diatas nampan plastik. Pada masing-masing vial plastik, diletakkan satu lembar daun kedelai dan satu ekor larva ulat grayak instar tiga. Pada setiap perlakuan digunakan hewan uji sebanyak lima ekor dengan pengulangan sebanyak tiga kali untuk tiap konsentrasi dan kontrol. Setiap larva dipaparkan dengan daun kedelai yang direndam pada ekstrak daun bintaro. Efektivitas pengaruh ekstrak daun bintaro terhadap ulat grayak dilakukan dengan mengamati waktu berhenti makan (time of stop feeding) dan mortalitas (tingkat kematian larva). Jumlah larva yang telah mengalami berhenti makan ditentukan dengan rumus sebagai berikut:

$$
\operatorname{Bm}(\%)=\frac{b}{n} \times 100
$$

dimana $\mathrm{Bm}$ merupakan persentase berhenti makan larva, b merupakan jumlah larva yang berhenti makan, dan $\mathrm{n}$ merupakan jumlah larva uji. Waktu berhenti makan diamati pada 1, 2, 8, 20, 22 dan 24 jam setelah aplikasi (JSA). Selain itu, mortalitas larva ulat grayak diamati 24,48 , 72, 96, 120, 144 dan 168 JSA.

\section{Analisis Data}

Data jumlah larva yang berhenti makan dan tingkat kematian (mortalitas) larva dianalisis dengan uji ANOVA. Jika menunjukkan perbedaan nyata maka dilanjutkan dengan uji Tukey-HSD ( $\alpha=5 \%)$ menggunakan program SPSS 16.0.

HASIL DAN PEMBAHASAN

Pengaruh Ekstrak Daun Bintaro (Cerbera odollam) terhadap Waktu Berhenti

\section{Makan (Stop Feeding) Larva Ulat Grayak (Spodoptera litura)}

Berdasarkan hasil penelitian diketahui bahwa larva $S$. litura hingga 2 jam setelah aplikasi (JSA) belum menunjukkan aktivitas berhenti makan (Tabel 1). Gejala keracunan yang ditandai dengan berhentinya aktivitas makan larva ditunjukkan pada saat 8 JSA pada perlakuan ekstrak daun bintaro dengan konsentrasi 20, 25 dan $30 \mathrm{~g} / \mathrm{L}$ sebanyak 6,67\%. Perlakuan ekstrak daun bintaro konsentrasi 10 dan $15 \mathrm{~g} / \mathrm{L}$ dapat menyebabkan larva S. litura berhenti makan 12 jam lebih lama dibandingkan dengan perlakuan konsentrasi 20, 25 dan $30 \mathrm{~g} / \mathrm{L}$.

Larva $S$. litura yang mengalami keracunan ekstrak daun bintaro menunjukkan gejala berhenti makan dan apabila larva disentuh maka akan tetap diam, gerakan melambat, nafsu makan berkurang dan akhirnya berhenti makan. Menurut Harwanto, Martono, Trisyono, and Wahyono (2012) adanya zat bioaktif yang dikandung oleh tanaman akan menyebabkan aktivitas larva terhambat, ditandai dengan gerakan larva melambat dan tidak memberikan respon gerak sehingga mengalami tahapan larva berhenti makan (stop feeding). Berdasarkan hasil penelitian ini juga diketahui bahwa larva $S$. litura yang berhenti makan pada masing-masing perlakuan menunjukkan nilai persentase yang semakin tinggi dengan semakin lamanya waktu aplikasi ekstrak.

Data hasil pengamatan larva S. litura yang berhenti makan berdasarkan analisis statistik menunjukkan belum ada perbedaan yang nyata hingga 8 JSA. Pada pengamatan 20 JSA menunjukkan perbedaan yang nyata $(\mathrm{p}<0,05)$ di antara perlakuan, begitupun pada perlakuan 22 dan 24 JSA. Selain itu, dapat dilihat juga bahwa semakin meningkatnya konsentrasi bahan nabati menyebabkan persentase larva $S$. litura yang berhenti makan semakin meningkat. 
Tabel 1. Persentase larva Spodoptera litura yang berhenti makan pada perlakuan ekstrak daun bintaro dengan berbagai konsentrasi

\begin{tabular}{|c|c|c|c|c|c|c|}
\hline \multirow{2}{*}{ Perlakuan } & \multicolumn{6}{|c|}{ Pengamatan ke- (Jam Setelah Aplikasi/JSA) } \\
\cline { 2 - 6 } & 1 & 2 & 8 & 20 & 22 & 24 \\
\hline $0 \mathrm{~g} / \mathrm{L}$ (kontrol) & $0,00 \mathrm{a}$ & $0,00 \mathrm{a}$ & $0,00 \mathrm{a}$ & $0,00 \mathrm{c}$ & $0,00 \mathrm{c}$ & $0,00 \mathrm{c}$ \\
\hline $10 \mathrm{~g} / \mathrm{L}$ & $0,00 \mathrm{a}$ & $0,00 \mathrm{a}$ & $0,00 \mathrm{a}$ & $13,33 \mathrm{bc}$ & $13,33 \mathrm{bc}$ & $13,33 \mathrm{bc}$ \\
\hline $15 \mathrm{~g} / \mathrm{L}$ & $0,00 \mathrm{a}$ & $0,00 \mathrm{a}$ & $0,00 \mathrm{a}$ & $26,67 \mathrm{abc}$ & $26,67 \mathrm{abc}$ & $26,67 \mathrm{abc}$ \\
\hline $20 \mathrm{~g} / \mathrm{L}$ & $0,00 \mathrm{a}$ & $0,00 \mathrm{a}$ & $6,67 \mathrm{a}$ & $53,33 \mathrm{ab}$ & $53,33 \mathrm{ab}$ & $53,33 \mathrm{ab}$ \\
\hline $25 \mathrm{~g} / \mathrm{L}$ & $0,00 \mathrm{a}$ & $0,00 \mathrm{a}$ & $6,67 \mathrm{a}$ & $53,33 \mathrm{ab}$ & $53,33 \mathrm{ab}$ & $53,33 \mathrm{ab}$ \\
\hline $30 \mathrm{~g} / \mathrm{L}$ & $0,00 \mathrm{a}$ & $0,00 \mathrm{a}$ & $6,67 \mathrm{a}$ & $60,00 \mathrm{a}$ & $60,00 \mathrm{a}$ & $60,00 \mathrm{a}$ \\
\hline
\end{tabular}

Keterangan: Angka-angka yang diikuti oleh huruf yang sama pada kolom yang sama menunjukkan tidak berbeda nyata berdasarkan uji Tukey-HSD pada taraf signifikansi $5 \%$.

Pada perlakuan 24 JSA untuk semua perlakuan telah menunjukkan gejala larva berhenti makan. Perlakuan $30 \mathrm{~g} / \mathrm{L}$ berbeda nyata $(\mathrm{p}<0,05)$ dengan perlakuan lainnya, tetapi tidak berbeda nyata $(\mathrm{p}>0,05)$ dengan perlakuan 15, 20 dan $25 \mathrm{~g} / \mathrm{L}$. Jumlah larva S. litura yang berhenti makan pada konsentrasi $30 \mathrm{~g} / \mathrm{L}$ pada 24 JSA adalah paling tinggi di antara perlakuan lainnya yaitu sebesar 60\%, lebih tinggi dibandingkan dengan perlakuan 20 dan $25 \mathrm{~g} / \mathrm{L}$ sebesar 53,33\% serta perlakuan $15 \mathrm{~g} / \mathrm{L}$ sebesar 26,67\%. Pada perlakuan $10 \mathrm{~g} / \mathrm{L}$ memiliki jumlah persentase larva berhenti makan sebesar 13,33\% dan kontrol memiliki persentase larva berhenti makan terendah sebesar 0\% (Tabel 1). Menurut Oguh et al. (2019), biopestisida berperan sangat cepat dalam menyebabkan serangga untuk berhenti makan yang tidak memelukan waktu hingga berhari-hari. Selain itu, biopestisida seringkali juga menyebabkan kelumpuhan segera terhadap hama.

\section{Pengaruh Ekstrak Daun Bintaro (Cerbera odollam) terhadap Mortalitas Larva Spodoptera litura}

Berdasarkan data persentase kematian larva S. litura diketahui bahwa pada pengamatan 24 jam setelah aplikasi (JSA) menunjukkan adanya kematian larva hanya pada perlakuan ekstrak daun bintaro konsentrasi $30 \mathrm{~g} / \mathrm{L}$ yaitu $6,67 \%$. Semua perlakuan pada 24 JSA berdasarkan hasil uji statistik menunjukkan tidak berbeda nyata ( $>0,05$ ) dibandingkan dengan kontrol (Tabel
2). Pengamatan kematian larva $S$. litura saat 48 JSA menunjukkan perbedaan yang nyata $(\mathrm{p}<0,05)$ antara $30 \mathrm{~g} / \mathrm{L}$ dan terhadap kontrol, 10 serta $15 \mathrm{~g} / \mathrm{L}$. Pada waktu 48 JSA dapat diamati bahwa terdapat peningkatan kematian larva pada beberapa perlakuan yakni 20, 25, dan 30 $\mathrm{g} / \mathrm{L}$ dibadingkan 24 JSA. Pada pengamatan ini persentase tertinggi terjadi pada perlakuan 30 $\mathrm{g} / \mathrm{L}$ sebesar 20\%, kemudian diikuti oleh perlakuan $25 \mathrm{~g} / \mathrm{L}$ dan $20 \mathrm{~g} / \mathrm{L}$ yaitu sebesar $6,67 \%$. Pada pengamatan 72 JSA terjadi peningkatan kematian larva $S$. litura yaitu sebesar $26,67 \%$ pada perlakuan $30 \mathrm{~g} / \mathrm{L}$, kemudian $20 \%$ pada perlakuan $20 \mathrm{~g} / \mathrm{L}$ dan 25 g/L. Selanjutnya, saat 96 JSA dijumpai kematian larva $S$. litura pada perlakuan $15 \mathrm{~g} / \mathrm{L}$ sebesar 6,67\%. Persentase kematian larva tertinggi terjadi pada perlakuan $30 \mathrm{~g} / \mathrm{L}$ yaitu mencapai 33,33\%, kemudian diikuti oleh perlakuan $20 \mathrm{~g} / \mathrm{L}$ dan $25 \mathrm{~g} / \mathrm{L}$ yaitu masingmasing sebesar $20 \%$.

Pada waktu 120 JSA dapat diamati bahwa terjadi peningkatan kematian larva pada beberapa perlakuan yakni 25 dan $30 \mathrm{~g} / \mathrm{L}$. Pada pengamatan ini persentase tertinggi terjadi pada perlakuan $30 \mathrm{~g} / \mathrm{L}$ sebesar $40 \%$, kemudian diikuti oleh perlakuan 25,20 dan $15 \mathrm{~g} / \mathrm{L}$ masing-masing sebesar 33,33, 20 dan 6,67\%. Pada pengamatan 144 JSA ini terjadi peningkatan kematian larva $S$. litura hanya pada perlakuan $20 \mathrm{~g} / \mathrm{L}$ yaitu sebesar $26,67 \%$. Persentase kematian larva tertinggi terjadi pada perlakuan $30 \mathrm{~g} / \mathrm{L}$ yaitu mencapai $40 \%$, kemudian diikuti oleh perlakuan 25 , 20, dan 15 
g/L masing-masing sebesar 33,33, 26,67, dan $6,67 \%$. Pada waktu 168 JSA dapat diamati bahwa terjadi peningkatan kematian larva pada beberapa perlakuan yakni 20 dan $25 \mathrm{~g} / \mathrm{L}$. Pada pengamatan ini persentase tertinggi terjadi pada perlakuan 30, 25 dan 20 masing-masing sebesar $40 \%$, kemudian diikuti oleh perlakuan $15 \mathrm{~g} / \mathrm{L}$ yaitu sebesar 6,67\%.

Kematian larva $S$. litura pada perlakuan 30 g/L sebesar $40 \%$ dicapai 120 JSA. Hal ini diduga disebabkan karena kandungan senyawa toksik yang lebih tinggi dibandingkan perlakuan lainnya. Ekstrak daun bintaro 20, 25 dan $30 \mathrm{~g} / \mathrm{L}$ digolongkan ke dalam ekstrak yang memiliki aktivitas sedang yang dicapai saat 168 JSA, sedangkan ektrak $15 \mathrm{~g} / \mathrm{L}$ termasuk ekstrak dengan kategori lemah. Kategori ektrak tidak aktif hingga 168 JSA berdasarkan hasil penelitian ini ditunjukkan oleh konsentrasi 10 g/L. Menurut Prijono (1998) aktivitas senyawa ekstrak diklasifikasikan dalam kategori sedang apabila tingkat mortalitas (m) hewan uji mencapai $40 \% \leq \mathrm{m}<60 \%$, kategori lemah apabila tingkat mortalitas (m) hewan uji mencapai $5 \% \leq \mathrm{m}<25 \%$ dan kategori tidak aktif apabila tingkat mortalitas (m) hewan uji $\mathrm{m}$ $<5 \%$.

Ekstrak yang terkandung di dalam daun bintaro berdasarkan hasil penelitian Utami (2010) memberikan respon positif terhadap alkena, amida, alkaloid, ester, flavonoid, steroid, saponin, dan tanin. Diduga senyawa kimia yang terkandung dalam daun bintaro memberikan efek terhadap mortalitas larva $S$. litura.

Tabel 2. Persentase kematian (mortalitas) larva Spodoptera litura pada perlakuan ekstrak daun bintaro dengan berbagai konsentrasi

\begin{tabular}{|c|c|c|c|c|c|c|c|}
\hline \multirow{2}{*}{ Perlakuan } & \multicolumn{7}{|c|}{ Pengamatan ke- (Jam Setelah Aplikasi/JSA) } \\
\cline { 2 - 8 } & 24 & 48 & 72 & 96 & 120 & 144 & 168 \\
\hline $0 \mathrm{~g} / \mathrm{L}($ kontrol) & $0,00 \mathrm{a}$ & $0,00 \mathrm{a}$ & $0,00 \mathrm{a}$ & $0,00 \mathrm{a}$ & $0,00 \mathrm{a}$ & $0,00 \mathrm{a}$ & $0,00 \mathrm{a}$ \\
\hline $10 \mathrm{~g} / \mathrm{L}$ & $0,00 \mathrm{a}$ & $0,00 \mathrm{a}$ & $0,00 \mathrm{a}$ & $0,00 \mathrm{a}$ & $0,00 \mathrm{a}$ & $0,00 \mathrm{a}$ & $0,00 \mathrm{a}$ \\
\hline $15 \mathrm{~g} / \mathrm{L}$ & $0,00 \mathrm{a}$ & $0,00 \mathrm{a}$ & $0,00 \mathrm{a}$ & $6,67 \mathrm{a}$ & $6,67 \mathrm{ab}$ & $6,67 \mathrm{ab}$ & $6,67 \mathrm{ab}$ \\
\hline $20 \mathrm{~g} / \mathrm{L}$ & $0,00 \mathrm{a}$ & $6,67 \mathrm{ab}$ & $20,00 \mathrm{ab}$ & $20,00 \mathrm{ab}$ & $20,00 \mathrm{bc}$ & $26,67 \mathrm{bc}$ & $40,00 \mathrm{~b}$ \\
\hline $25 \mathrm{~g} / \mathrm{L}$ & $0,00 \mathrm{a}$ & $6,67 \mathrm{ab}$ & $20,00 \mathrm{ab}$ & $20,00 \mathrm{ab}$ & $33,33 \mathrm{~cd}$ & $33,33 \mathrm{c}$ & $40,00 \mathrm{~b}$ \\
\hline $30 \mathrm{~g} / \mathrm{L}$ & $6,67 \mathrm{a}$ & $20,00 \mathrm{~b}$ & $26,67 \mathrm{~b}$ & $33,33 \mathrm{~b}$ & $40,00 \mathrm{~d}$ & $40,00 \mathrm{c}$ & $40,00 \mathrm{~b}$ \\
\hline
\end{tabular}

Keterangan: Angka-angka yang diikuti oleh huruf yang sama pada kolom yang sama menunjukkan tidak berbeda nyata berdasarkan uji Tukey-HSD pada taraf signifikansi $5 \%$.

Berdasarkan hasil pengamatan dapat diketahui bahwa jumlah kematian larva $S$. litura semakin meningkat sejalan dengan semakin lamanya waktu pengamatan pada perlakuan ekstrak lebih dari $10 \mathrm{~g} / \mathrm{L}$. Gejala kematian larva $S$. litura tampak pada larva yang memakan daun perlakuan dan mulai terjadi 24 jam setelah perlakuan. Larva $S$. litura yang masih hidup menunjukkan warna tubuh kehijauan dan aktif bergerak (Gambar 2a). Larva $S$. litura yang menunjukkan gejala keracunan semakin lama menunjukkan perubahan warna kulit (Gambar 2b-c).

Larva $S$. litura yang mati menunjukkan bentuk yang tetap utuh dengan warna tubuh yang menghitam (Gambar 2d). kematian ini diduga disebabkan oleh efek racun dari ekstrak yang diberikan. Penelitian Utami (2010) menunjukkan bahwa larva $S$. litura yang mati akibat ekstrak daun bintaro akan mengering, kaku, tubuhnya berwarna coklat kehitaman dan mengecil. Lama kelamaan tubuh larva yang mati ini akan lunak dan mengering. Gejala umum kematian larva diawali dengan paralisis/kelumpuhan. Gejala keracunan demikian biasa dikenal dengan efek knock down.

Hasil penelitian ini mengindikasikan bahwa ekstrak daun bintaro berpotensi dijadikan biopestisida untuk pengendalian populasi larva ulat grayak melalui aplikasi secara penyemprotan pada lahan pertanian. Selain itu, ekstrak dapat disiapkan dengan cara perendaman daun bintaro di dalam air atau 
pelarut lainnya, misalnya: etanol atau lainnya sebelum diaplikasikan ke lahan.



Gambar 2. Larva Spodoptera litura yang belum masih sehat (a) dan menunjukkan gejala keracunan (bc) dan mati (d) karena aplikasi ekstrak daun bintaro (Cerbera odollam). Bar menunjukkan $0.5 \mathrm{~cm}$.

\section{SIMPULAN}

Biopestisida nabati daun bintaro berpotensi digunakan sebagai agen hayati ulat grayak. Persentase larva yang berhenti makan dan mortalitas larva ulat grayak. semakin meningkat dengan semakin lamanya waktu pengamatan setelah aplikasi. Mortalitas tertinggi terjadi pada ektrak daun bintaro dengan konsentrasi 20, 25 dan 30 g/L yaitu sebesar $40 \%$.

\section{DAFTAR PUSTAKA}

Abizar, M., \& Prijono, D. (2010). Aktivitas insektisida ekstrak daun dan biji Tephrosia vogelii J.D. Hooker (Leguminosae) dan ekstrak buah Piper cubeba L. (Piperaceae) terhadap larva Crocidolomia pavonana (f.) (Lepidoptera: Crambidae). Jurnal Hama dan Penyakit Tumbuhan Tropika, 10, 112.
Asmaliyah, Hadi, E. E. W., Utami, S., Mulyadi, K., Yudhistira, \& Sari, F. W. (2010). Pengenalan Tumbuhan Penghasil Pestisida Nabati dan Pemanfaatannya Secara Tradisional. Jakarta: Pusat Penelitian dan Pengembangan Produktivitas Hutan Kementerian Kehutanan RI.

Chu, S.-Y., Singh, H., Ahmad, M. S., \& Mamat, A. S. (2015). Phytochemical screening of antifungal biocompounds from fruits and leaves extract of Cerbera odollam Gaertn. Malaysian Applied Biology, 44(3), 75-79.

Erdogan, P., Yildirim, A., \& Sever, B. (2012). Investigations on the Effects of Five Different Plant Extracts on the Two-Spotted MiteTetranychus urticaeKoch (Arachnida: Tetranychidae). Psyche: A Journal 
of Entomology, 2012, 1-5. doi:10.1155/2012/125284

Harwanto, Martono, E., Trisyono, A., \& Wahyono. (2012). Pengaruh ekstrak limbah daun tembakau madura terhadap aktivitas makan larva Spodoptera exigua. Biosantifika, 4(1), 1-9.

Hasnah, Husni, \& Fardhisa, A. (2012). Pengaruh ekstrak rimpang jeringau (Acorus calamus L.) terhadap mortalitas ulat grayak Spodoptera litura F. Jurnal Floratek, 7, 115-124.

Marrone, P. G. (2019). Pesticidal natural products - status and future potential. Pest Manag Sci, 75(9), 2325-2340. doi:10.1002/ps.5433

Mboussi, S. B., Ambang, Z., Kakam, S., \& Beilhe, L. B. (2018). Control of cocoa mirids using aqueous extracts of Thevetia peruviana and Azadirachta indica. Cogent Food \& Agriculture, 4(1), 1-13. doi:10.1080/23311932.2018.143047 0

Oguh, C. E., Okpaka, C. O., Ubani, C. S., Okekeaji, U., Joseph, P. S., \& Amadi, E. U. (2019). Natural Pesticides (Biopesticides) and Uses in Pest Management- A Critical Review. Asian Journal of Biotechnology and Genetic Engineering, 2(3), 1-18.

Prijono, D. (1998). Insecticidal activity of meliaceous seed extracts against Crocidolomia binotalis Zeller (Lepidoptera: Pyralidae). Buletin Hama dan penyakit Tumbuhan, 10(1), 1-7.

Rahman, M. S., Faisal, A., Hasan, C. M., Ahsan, M., \& Masud, M. M. (2017). Chemical and Biological Investigations of Cerbera odollam Gaertn. Dhaka University Journal of Pharmaceutical Sciences, 16(2), 179-186.

Rizal, S., Dewi, H., \& Utomo, T. P. (2015). Pengaruh jenis pelarut terhadap aktivitas antibakteri ekstrak daging dan biji buah bintaro (Cerbera manghas L.). Jurnal Teknologi Industri \& Hasil Pertanian, 20(1), 51-64.

Sa'diyah, N. A., Purwani, K. I., \& Wijayawati, L. (2013). Pengaruh ekstrak daun bintaro (Cerbera odollam) terhadap perkembangan ulat grayak (Spodoptera litura F.). Jurnal Sains dan Seni Pomits, 2(2), 2337-3520.

Salinas-Sánchez, D. O., Aldana-Llanos, L., Valdés-Estrada, M. E., GutiérrezOchoa, M., Valladares-Cisneros, G., \& Rodríguez-Flores, E. (2012). Insecticidal Activity ofTagetes erectaExtracts onSpodoptera frugiperda(Lepidoptera: Noctuidae). Florida Entomologist, 95(2), 428432. doi:10.1653/024.095.0225

Sholahuddin, A. H., Subchan, W., \& Prihatin, J. (2018). Toxicity of granules of bintaro leaf extract (Cerbera odollam Gaertn.) on armyworm (Spodoptera litura Fab.). Bioedukasi, 16(1), 15-21.

Sifa, A., Prijono, D., \& Rauf, A. (2013). Keefektifan tiga jenis insektisida nabati terhadap kutu putih pepaya Paracoccus marginatus dan keamanannya terhadap larva kumbang predator Curinus coeruleus. Jurnal Hama dan Penyakit Tumbuhan Tropika, 13(2), 124-132.

Somsroi, P., \& Chaiyong, S. (2016). Effect of suicide tree crude extract (Cerbera odollam Gaerth.) on common cutworm (Spodoptera litura Fabricius). Rajabhat Agriculture Journal, 15(1), 16-21.

Susilo, A., Haryanta, D., \& Sa'adah, T. T. (2019). Response of Riptortus linearis towards the aplication of Bintaro (Cerbera manghas) leaf extract. EurAsian Journal of BioSciences, 13, 2217-2224.

Utami, S. (2010). Aktivitas insektisida bintaro (Cerbera odollam Gaertn) 
terhadap hama Eurema spp. Pada skala laboratorium. Jurnal Penelitian Hutan Tanaman, 7(4), 211-220.

Yooboon, T., Pengsook, A., Ratwatthananon, A., Pluempanupat, W., \& Bullangpoti, V. (2019). A plant-based extract mixture for controlling Spodoptera litura (Lepidoptera: Noctuidae). Chemical and Biological Technologies in Agriculture, 6(1). doi:10.1186/s40538-019-0143-6 